\title{
Analysis of light tubes in interior daylighting system for building
}

\author{
Badri Narayan Mohapatra ${ }^{1}$, M. Ravi Kumar ${ }^{2}$, Sushanta K. Mandal ${ }^{3}$ \\ ${ }^{1}$ Department of Electronics and Communication, CUTM, India \\ ${ }^{2}$ Department Electronics and Communication Engineering, MNIT, India \\ ${ }^{3}$ Department Electronics and Communication Engineering, Sharda University, India
}

\begin{tabular}{l} 
Article Info \\
\hline Article history: \\
Received Apr 15, 2019 \\
Revised Jun 16, 2019 \\
Accepted Jun 30, 2019 \\
\hline
\end{tabular}

Keywords:

Daylight

Energy saving

Illuminance

Light design

Optical tube

\begin{abstract}
Analysis of vertical light tubes, and diffuser as daylighting system in buildings is presented. The solar light energy is directly addressed to the chosen area of the building with a light tube and diffuser guiding structure. This work highlights illuminance obtained by light tubes in a three storied office building. Field investigation with a scaled prototype and simulations with HOLIGILM, and DIALux are analyzed. It is observed that light tubes can offer large savings in electricity usage by using natural daylight.
\end{abstract}

Copyright $(2020$ Institute of Advanced Engineering and Science. All rights reserved.

\section{Corresponding Author:}

Badri Narayan Mohapatra, Department of Electronics and Communication, CUTM, Paralakhemundi, 761211, India.

Email: badri1.mohapatra@gmail.com

\section{INTRODUCTION}

Light tube as a source is designed to direct light into deep areas within buildings where daylight cannot reach. The combined use of windows and light tubes can improve the daylighting within a room. By multi-reflection mechanism, light tubes transmit sunlight which is more uniform. Various advantages of daylighting for human health and comfort are described in [1-3]. Daylight systems can reduce heating and cooling cost for buildings as reported in [4]. Daylighting with the use of light tube systems can have a positive influence in providing daylight to interior areas of buildings which receive very less lighting from windows [5-8]. The use of daylight or natural light can reduce the energy consumption by up to $30 \%$ [9]. The performance of light tubes has been investigated in a number of studies [10-12]. The use of light tubes offers significant advantages over artificial lighting, namely energy savings and physiological benefits [13]. In recent years, solar light tubes have firmly set their foot within the UK market place [14]. A light tube's ability to bring light into core area within big buildings has been noticed from a long time ago by Hanneborg from Norway in 1900 [15]. Fiber optic lighting also has very good transmission properties but is very expensive as compared to light tubes [16]. The light tube has become popular in the development of daylighting technology. Moreover, the technology is an efficient method of transporting light to areas of a building with limited daylight exposure [17]. Diffuser in some literature is found to be very effective in the performance of daylight systems [18].Nowadays, the applications of tubular daylighting devices are many, such as in rooms without windows, tunnels, underground passages, and corridors [19]. Light tubes [20-22], and double light tubes [23, 24] are used in underground rooms. This work focuses on how to meet sustainable goals by utilizing different parameters of light tubes. The location is chosen as Bhubaneswar, Odisha in India (present address of corresponding author) and three different cases for illuminating a room are considered. 
The tubes are not expensive, and justify their use to bring daylight into deep-plan spaces. Windows, and skylights are usually not capable of illuminating the core of a building. Light tubes are the best method for daylighting, and ensure adequate illuminance levels. This work focuses on the the effectiveness of light tube performance based on simulation, experiments and numerical charaterization for predicting illuminance levels which help to indentify the proper dimensions of required light tube.

Section 2 describes different daylight collection techniques and methods of diffusing the natural light into a building. The different cases for illuminating a room are elaborated in Section 3 and the corresponding results are discussed in Section 4. Section 5 describes prototype design and implementation. Lighting design with LEDs is described in Section 6. The article is concluded in Section 7.

\section{DAYLIGHT COLLECTOR}

As solar radiation is only available during daytime, the energy must be collected in an efficient manner to make maximum possible use of daylight hours [25]. The active utilization of daylight depends on exterior conditions as well as on technologies applied in designing the light tubes [26]. Light tubes are able to transport and distribute natural light without heat transfer in dark rooms [27]. Commercially available light tube systems consist of three main components: daylight collector, light tube and diffuser. The collector is mounted over a roof which normally appears like a clear dome structure, and it removes undesirable ultra violet (UV) light and seals the light tube against the rain and dust particles. Different types of light transportation are possible, by using a hollow tube (Solatube), polymer fiber (Parans), and special quartz fiber (Himawari) [28]. Other daylighting methods such as solar pipe, SunScope, light tube, light pipe, and tubular skylight are also available [29].

\subsection{Light Tube}

Light transmission efficiency is an important indicator of light tube performance, and it depends on geometry, optical parameters of light tube, and sky conditions [30]. The principle of guiding light in a tube is based on multiple reflections. These tubes are normally made by alloys of aluminium. Light intensity is lost in case of angled, long or flexible tubes. This research focused on the simulation and scaled experiments of straight light tubes on a rectangular surface as given in Figure 1. Light tubes are used for transportation of light to unlit portions of a building with uniform distribution of illumination level. The application of light tube can be considered in factories, schools, warehouses, institutions, corridors and offices for commercial purpose, and in kitchens, living rooms, staircases, and toilets for residential purpose. In diffused weather conditions, silver coated tubes are used to transfer maximum amount of sunlight.

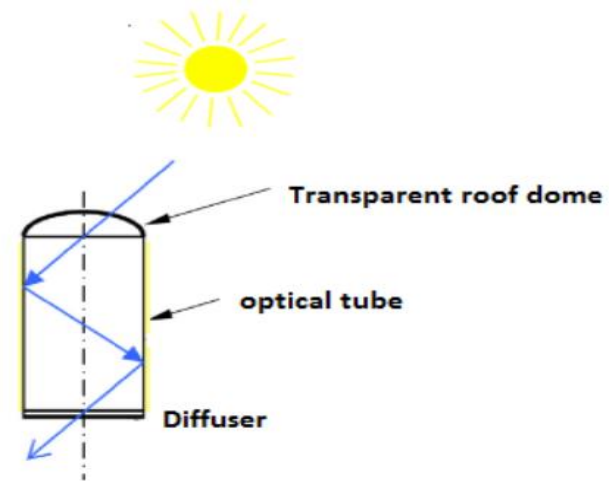

Figure 1. Principle of light guiding in a tube

\subsection{Diffuser}

A diffuser scatters or spreads out light uniformly, like a lighting source. Diffusers are one of the main design tools for altering the (acoustic) conditions of rooms, semi enclosed spaces and outdoor environment [31]. Transparency will vary according to material properties. Depending on the required usage, different diffusers are chosen. For example, clear diffuser (made by polycarbonate) is preferred in corridors where quantity of light has more priority. But for uniform daylighting, opal diffusers are used. By using a Perfect Reflecting Diffuser (PRD), brightness is same from all points of view. Several types of optical diffusers using opal glass, ground glass, holographic, and greyed glass exist. 


\section{DESCRIPTION OF A CASE STUDY}

Different devices, and appliances consume electricity with varying power. By choosing to use power from a free source like Sun, one can save more energy. The modes, and duration of appliances' use determines the overall electricity consumption [32]. Designers/ architects have an option to measure and calculate the lighting level and design buildings in such a way that there is minimum use of artificial lighting, so that the overall electric load will be reduced.

An office building in Bhubaneswar is considered for this study. It consists of thirty identical private offices which are connected through a central aisle that runs along the centre on all three storeys. The building is oriented as North and South facing as shown in Figure 2. The location and daylighting system parameters used for simulation are described in Tables 1 and 2.

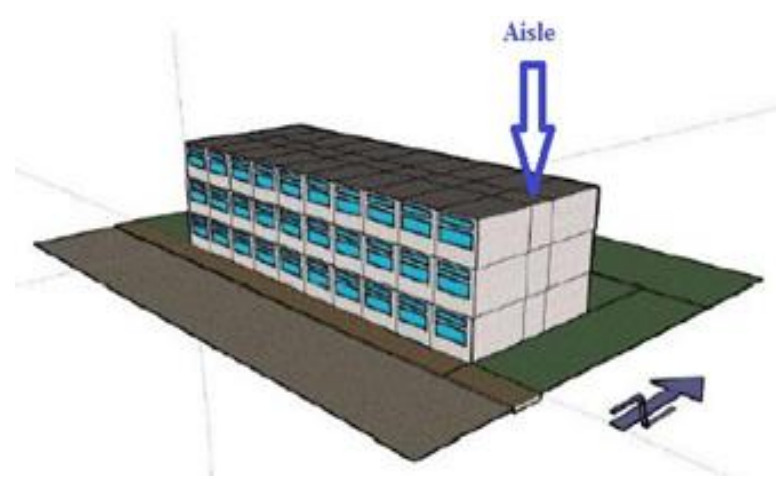

Figure 2. Sketchup visualization of the investigated office building

Table 1. Simulation Parameters Associated with Location

\begin{tabular}{ccccc}
\hline Location & Latitude & Longitude & Sky condition & Day \\
\hline Bhubaneswar & 20.25 & -85.83 & Overcast & 30th Nov. \\
\hline
\end{tabular}

Table 2. Daylighting System Parameters of

\begin{tabular}{cc}
\multicolumn{2}{c}{ Room, Tube, and Diffuser } \\
\hline Aisle & Tube \\
\hline Length $=3 \mathrm{~m}$ & Reflectance $=0.934$ \\
Width $=3 \mathrm{~m}$ & Length $=5.8 \mathrm{~m}$ \\
Height $=2.8 \mathrm{~m}$ & Diameter (D) $=0.52 \mathrm{~m}$ \\
\hline
\end{tabular}

For simulation we have considered the length of light tube as 5.8 meters to illuminate the ground oor aisle, because height of two floors is $(2.8 * 2=5.6)$ meters, and an extra $20 \mathrm{~cm}$ is kept protruding upwards as shown in Figure 3. Simulations are carried out using a free software, HOLIGILM. This user friendly software gives an option to chose any one out of 15 sky models for measurement. HOLIGILM works with light tubes of different properties in one simulation. The weather condition is considered as overcast, and the parameters for simulation are as shown in Table 2. Transmittance of the diffuser is considered to be $75 \%$ for better performance [33]. The luminous intensity of hollow light guides is determined using an extended HOLIGILM solution [34].

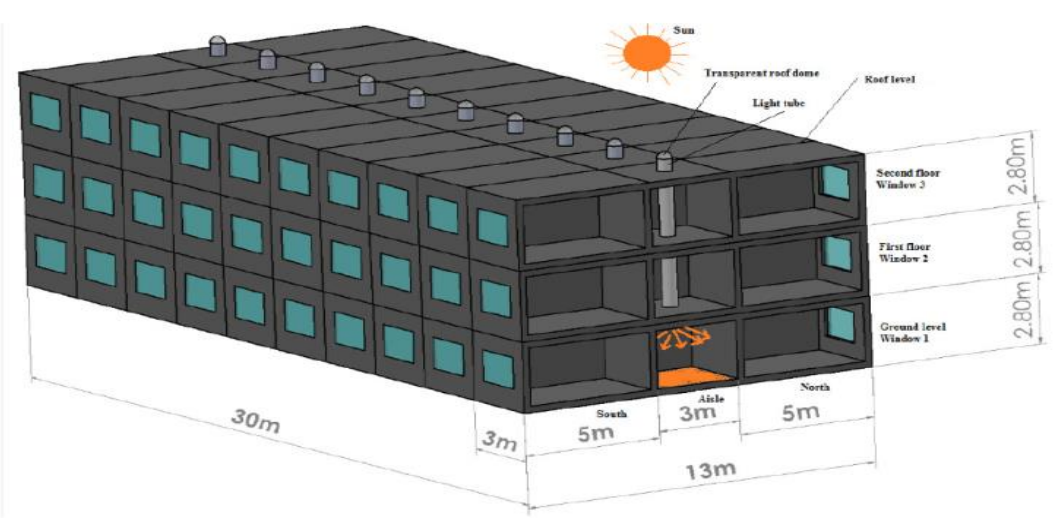

Figure 3. Light tube of 5.8 meters to illuminate the ground floor aisle 


\section{SIMULATION RESULTS}

Simulation results are obtained by varying parameters of light tube and changing the position, and number of tubes. To simplify the analysis of results, following representations are used. The circumference, and crossectional area of a single tube are represented by ' $\mathrm{C} 1$ ', and 'A1' respectively. Similarly, the circumference, and crossectional area of double tube are represented by ' $\mathrm{C} 2$ ', and 'A2' respectively. The illuminance on ground surface is represented as ' $\mathrm{L}$ '.

\subsection{Case-1: Single Light Tube}

The ground surface is illuminated uniformly or directly by light tube [35]. The workplane illuminance is most usefull output of aisle, and is shown in Figure 4 for an illuminance of 200 Lux. For a light tube of height $5.8 \mathrm{~m}$, diameter of $0.76 \mathrm{~m}$ is needed to get an illuminance of $200 \mathrm{Lux}$.

When a single light tube is placed in the middle of aisle, then illuminance depends on diameter of tube. As shown in Table 3, with increase of tube diameter, illuminance also increases.

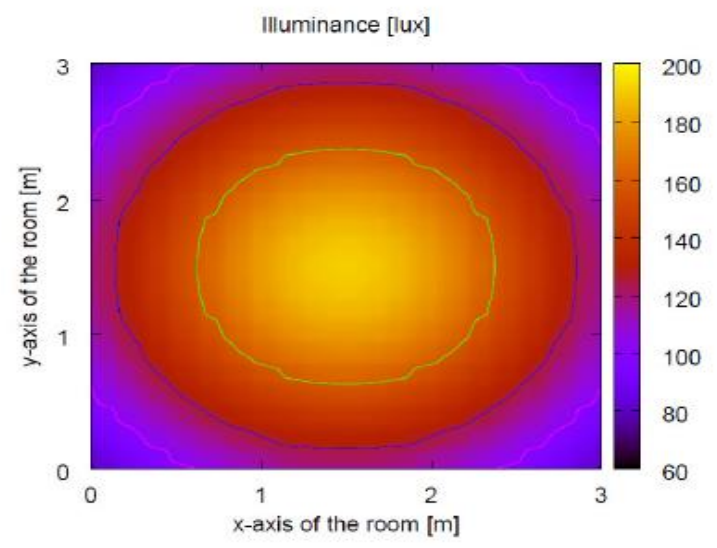

Figure 4. Workplane illuminance of aisle by a single light tube of height $5.8 \mathrm{~m}$, and diameter $0.76 \mathrm{~m}$

Table 3. Illuminance of Aisle for Different Diameters of Single Light Tube

\begin{tabular}{ccc}
\hline XY Position & $\mathrm{D}(\mathrm{m})$ & $\mathrm{L}(\mathrm{lux})$ \\
\hline$(1.5,1.5)$ & 0.46 & 55 \\
$(1.5,1.5)$ & 0.58 & 100 \\
$(1.5,1.5)$ & 0.68 & 150 \\
$(1.5,1.5)$ & 0.76 & 200 \\
\hline
\end{tabular}

\subsection{Case-2: Double Light Tube}

Since the office aisle is $3 \mathrm{~m} \times 3 \mathrm{~m}$, two light tubes can be used. Schematic of actual working plane with the number of tubes is shown in Figure 5. In case of single light tube, it is placed in middle of the working plane which is represented by location $(1.5,1.5)$ corresponding to $\mathrm{X}$, and Y positions. In case of two light tubes, these are placed according to distance between the two tubes. In Figure 5, the positions of X, and $\mathrm{Y}$ are $(1,1)$, and $(1.8,1.8)$. When two light tubes are used without any distance between the two, they are refered to as a 'Double Light Tube'.

Entrance-point of light tube usually comprises of a dome located on the roof of the house or one of its outer walls. The function of dome is collecting as much sunlight as possible inside the tube. The other end of the tube has a diffuser for spreading the light inside a room. Light transmission efficiency is greatest within the building if the light tube is short and straight [36].

Figure 6 shows the workplane illuminance for 200 Lux using a double light tube of height $5.8 \mathrm{~m}$, and diameter $0.58 \mathrm{~m}$ of each tube. The workplane illuminance of the aisle using double light tube of different diameters is shown in Table 4. 


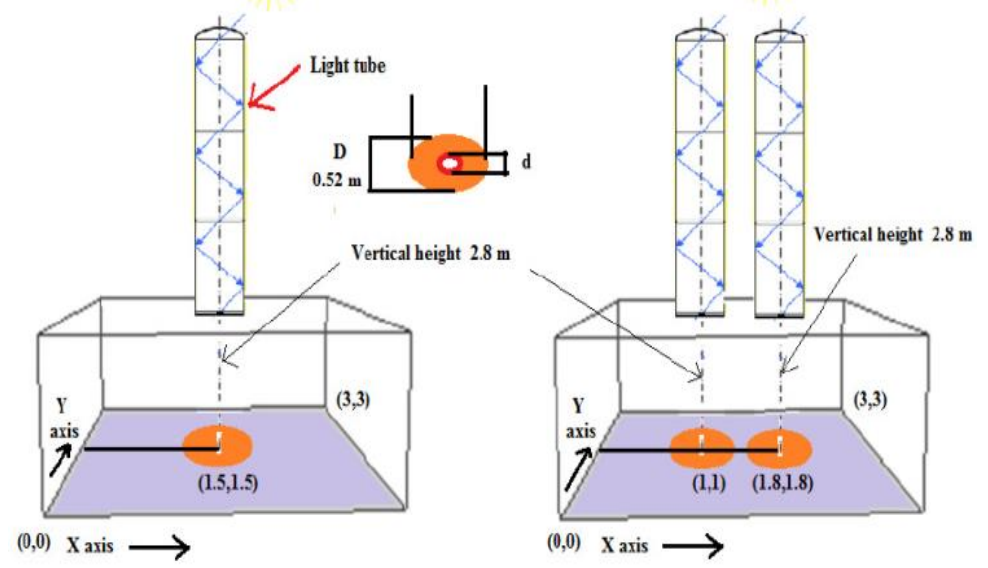

Figure 5. Schematic view of a room with single light tube, and double light tube

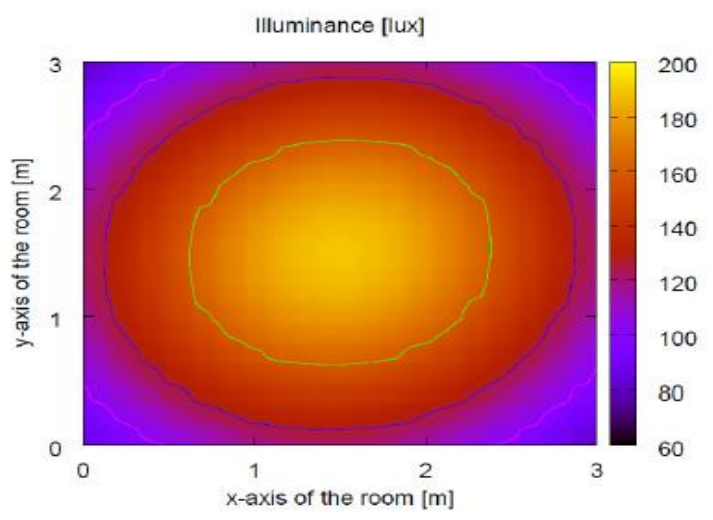

Figure 6. Workplane illuminance of aisle by double light tube of height $5.8 \mathrm{~m}$, and diameter $0.58 \mathrm{~m}$ for each tube

Table 4. Illuminance of Aisle for Different Diameters of Double Light Tube

\begin{tabular}{cccc}
\hline XY Position & XY Position & D (m) & Illuminance (lux) \\
\hline$(1.27,1.27)$ & $(1.73,1.73)$ & 0.46 & 110 \\
$(1.24,1.24)$ & $(1.76,1.76)$ & 0.52 & 150 \\
$(1.21,1.21)$ & $(1.79,1.71)$ & 0.58 & 200 \\
\hline
\end{tabular}

Comparing Tables 3 and 4 one can easily understand that the aisle illuminace is only 100 Lux by single light tube of diameter $0.58 \mathrm{~m}$. If double light tube is used then aisle will be illuminated with 200 Lux for a diameter of $0.58 \mathrm{~m}$ each. A minimum illuminance of 200 Lux [37] is considered to be acceptable for visibility in corridors.

The simulation results of Table 5 are plotted in Figures 7 and 8. Figure 7 shows theilluminance as a function of total circumference of light tubes and Figure 8 shows the simulated values of illuminance as a function of complete cross-sectional area occupied by light tubes. If we compare both single, and double light tubes in Table 5, Figure 7, and Figure 8, it is found that, for the same value of illuminace, both circumference, and crossectional area of single light tube is less as compared to double light tube. Since the circumference is less for a single light tube, the quantity of light tube needed is less for a single light tube, and hence is economical than a double light tube. Multiple tubes can be used which will depend on room size and choice of architectural designer. 
Table 5. Comparision between single and double light tube

\begin{tabular}{ccccc}
\hline $\mathrm{L}(\mathrm{lux})$ & $\mathrm{C}_{1}(\mathrm{~m})$ & $\mathrm{A}_{1}\left(\mathrm{~m}^{2}\right)$ & $\mathrm{C}_{2}(\mathrm{~m})$ & $\mathrm{A}_{2}\left(\mathrm{~m}^{2}\right)$ \\
\hline 110 & 1.880 & 0.282 & 2.89 & 0.332 \\
130 & 2.010 & 0.321 & 3.016 & 0.360 \\
150 & 2.136 & 0.363 & 3.26 & 0.424 \\
160 & 2.199 & 0.384 & 3.38 & 0.458 \\
200 & 2.387 & 0.453 & 3.64 & 0.528 \\
220 & 2.450 & 0.477 & 3.76 & 0.564 \\
\hline
\end{tabular}

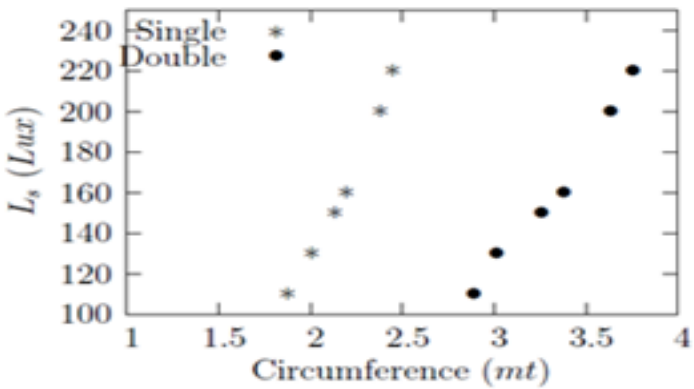

Figure 7. Illuminance of single and double light tubes with respect to total circumference of light tubes

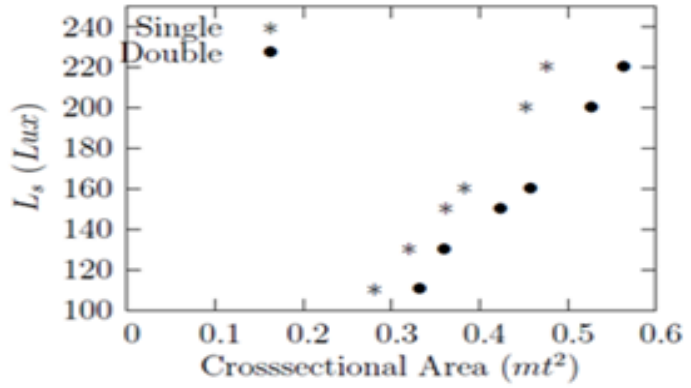

Figure 8. Illuminance of single and double light tubes with respect to complete crossectional area occupied by light tubes

\subsection{Case-3: Two Separate Light Tube}

In this case a tube diameter of $0.52 \mathrm{~m}$ is used, but two tubes are placed nearer to the walls with a distance of $10 \mathrm{~cm}$ from walls as shown in Figure 9. A maximum illuminance of $120 \mathrm{Lux}$ is obtained on the door as shown in Figure 10. This is not advantageous as compared to double light tube, since the level of illuminance is lower by 30 Lux. A double light tube in middle position provides uniformity as well. We conclude that having two separate light tubes gives no advantage in comparison with a double light tube in the middle.

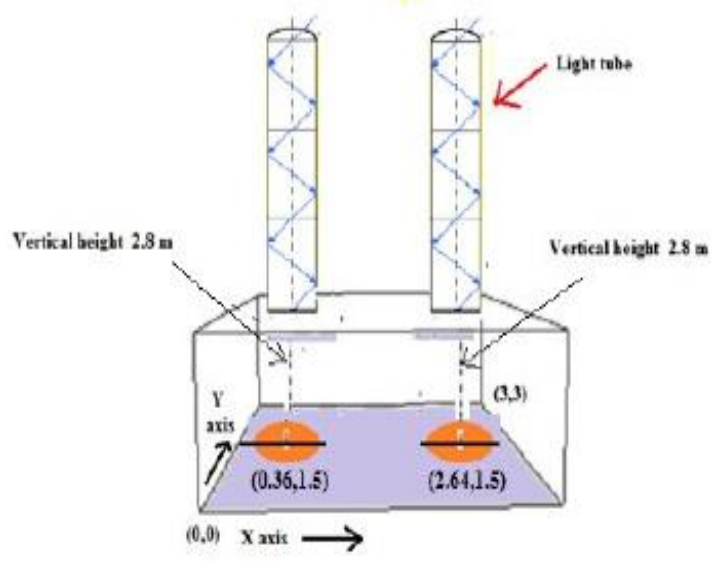

Figure 9. Schematic of two separate light tubes with respect to workplane



Figure10. Output obtained from two separate light tubes on the workplane

A diameter of $0.76 \mathrm{~m}$ for the single light tube is sufficent for the above mentioned case to illuminate the aisle properly with a visibility of 200 Lux. From experimental point of view, any installations or insulations are not required for light tubes, and are specially useful in aisles, and bathrooms that do not have direct access to sunlight. These structures reduce energy consumption and save electricity. 


\section{PROTOTYPE DESIGN AND IMPLEMENTATION}

A prototype of the simulated aisle is designed and setup using plywood. It is implemented to validate the obtained simulation results. It is modeled with reduced dimensions which have a fixed ratio of 1:15 with the simulation model. The prototype is expected to enable estimation of actual light levels (Lux) resulting from a tube of chosen dimensions. Different parameters had to be considered while modeling the prototype. A luxmeter was used to measure the illuminance levels in the prototype. Measurements were taken in an intermediate sky condition.

Figure 11 shows photographs of aluminium light tubes of different diameters which are used in the prototypes implemented with a single light tube, and a double light tube. Length of all the tubes is $386 \mathrm{~mm}$. The bottom portion of tubes is covered with diffusers, but domes at the top could not be found for such small dimensions. A $15 \mathrm{~cm}$ scale is placed along side the tubes to give an impression of the approximate length, and diameter of the tubes.

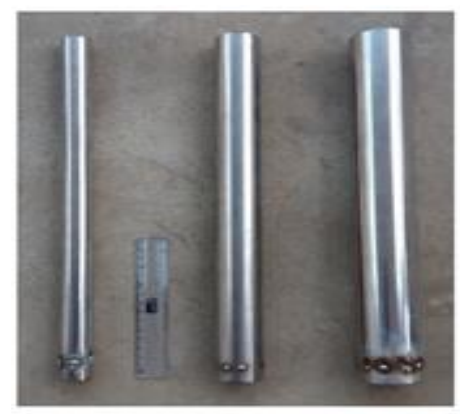

Figure 11. Aluminium tubes used to implement prototypes of single, and double light tubes of diameters $25 \mathrm{~mm}, 40 \mathrm{~mm}$ and $50 \mathrm{~mm}$

Figure 12 and Figure 13 are photographs of implemented prototypes for single, and double light tubes respectively. Total length of the prototype corresponds to a section consisting of a single north block room, an aisle, and a single south block room. The interior of the prototype is designed in such a way that light can not enter the aisle from either north or south rooms.

\subsection{Case-1: Single Light Tube}

Sunlight is collected directly without a dome and is transmitted down by multiple specular reflections to the interior or core of the room. It was decided to implement a prototype model that would enable measurement of illuminance levels (Lux) with a proper aspect ratio as that of our simulation model. An aluminium tube with a height of $386 \mathrm{~mm}$, and diameter of $50 \mathrm{~mm}$ is designed. The tube is placed in middle of the aisle as shown in Figure 12.

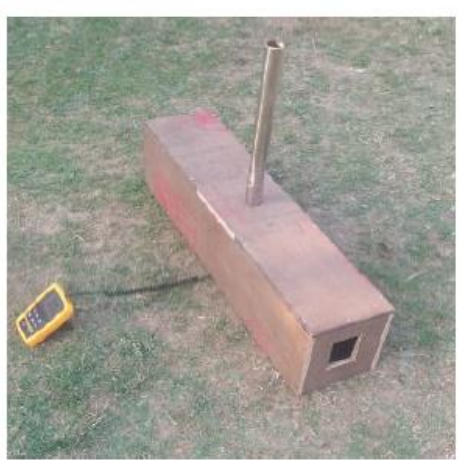

Figure 12. Implemented prototype with a single light tube

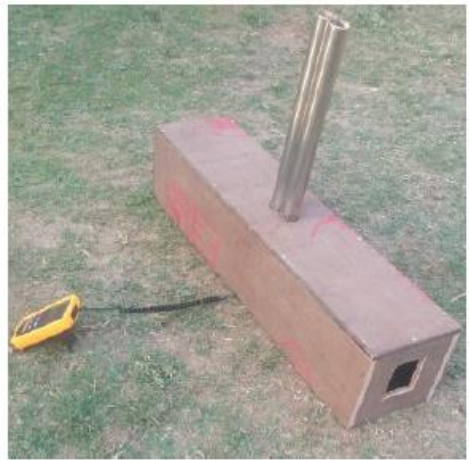

Figure 13. Implemented prototype with a double light tube 


\subsection{Case-2: Double Light Tube}

To decide on configuration and size of light tubes necessary for a prototype or a real model the factors to be taken into consideration are type of tubes being used, size of the room, and external illuminance. If a room has windows which receive illuminance, contribution can be added with light tubes to increase the light (Lux) level.

When connfiguration, and size of a room varies, it is difficult to determine the required length, and diameter of a light tube for a given illuminance value. Prediction of the required values becomes possible with the aid of design tools, or by experienced personnel. Giving priority to installation of light tubes, electric lighting requirment reduces to a minimum if the light tubes are configured correctly. By properly installing light tubes, energy bills shall reduce which is beneficial to the environment as well.

To verify the illuminance values obtained by measurement, simulations were carried out with the same dimensions as that of the prototype. There was no provision to design simulation models for light tubes of diameter less than $40 \mathrm{~mm}$ with the simulation tool used here. Table 6 shows the obtained illuminance values from the prototype, and simulations. Here, the $\mathrm{Lm}_{1}, \mathrm{Lso}_{1}$ and $\mathrm{Lm}_{2}, \mathrm{LsO}_{2}$ value written in terms of lux.

Table 6. Measured and Simulated Illuminance, Values for Proto Type Dimensions

\begin{tabular}{ccccccccc}
\hline $\mathrm{D}(\mathrm{mm})$ & $\mathrm{C}_{1}(\mathrm{~m})$ & $\mathrm{A}_{1}\left(\mathrm{~m}^{2}\right)$ & $\mathrm{Lm}_{1}$ & $\mathrm{LsO}_{1}$ & $\mathrm{C}_{2}(\mathrm{~m})$ & $\mathrm{A}_{2}\left(\mathrm{~m}^{2}\right)$ & $\mathrm{Lm}_{2}$ & $\mathrm{LsO}_{2}$ \\
\hline 25 & 0.078 & 0.0005 & 12 & - & 0.156 & 0.0010 & 70 & - \\
40 & 0.126 & 0.0012 & 85 & 100 & 0.253 & 0.0024 & 325 & 200 \\
50 & 0.157 & 0.0019 & 159 & 180 & 0.315 & 0.0038 & 462 & 320 \\
\hline
\end{tabular}

\section{LIGHTING DESIGN WITH LEDS}

LEDs are useful to supplement lighting when the internal illuminance goes below the minimum value, as in night time. Simulation of lighting design with LEDs on DIALux software is used for this study. The same building as shown in Figure 3 is considered in this simulation also. Twelve LEDs, each with a luminous efficiency of $42.6 \mathrm{Lm} / \mathrm{W}$ are used in both south, and north offices. Seventy five such LEDs are used in the whole aisle to get desired illuminance of approximately 200 Lux. Figure 14 shows the position of LEDs (dots near the roof), which is designed with DIALux. Illuminance on the workplane is indicated by different colours representing varying illuminance levels in the same figure.

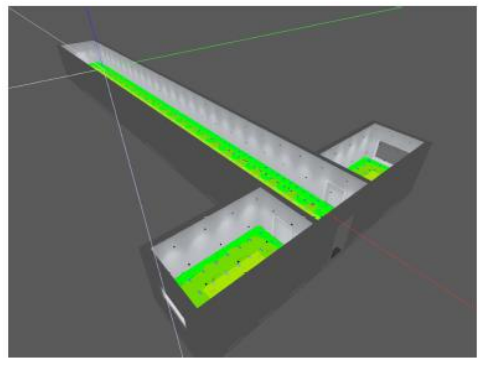

Figure 14. LED arrangement and output on workplane in south, north and aisle of the building

A comparative study of lighting technologies [38] is shown in Table 7. Based on available data Table 7, energy conservation with the use of light tubes in the aisles is estimated by considering minimum power consumption of LEDs. Since the required illuminance in aisles is $200 \mathrm{Lux}$, it is assumed that a 3 Watt LED would be sufficient. Power consumed by LEDs (75 LEDs $\times 3$ Watts/LED) is 225 Watts. Energy consumption by these LEDs for a day ( 8 hours), when daylight is available, amounts to $1.8 \mathrm{KWh}$. For all aisles in the building, energy consumption would be $5.4 \mathrm{KWh}$. Accounting for weekends, and holidays, the number of working days in an year would be approximately 250 . Hence, power consumption by LEDs in the aisles for a whole year would be $1350 \mathrm{KWh}$. Researchers are also working on different solar PV grid point system to reduce and save energy [39, 40]. Daylighting can reduce the scarcity of energy [41] and saving energy is the huge requirement to this world [42]. 
Table 7. Comparative Study of Modern Lighting Systems [38]

\begin{tabular}{ccc}
\hline Type & Power consumed (watts) & Illuminance (lux) \\
\hline Incandescent & 40 & $400-500$ \\
CFL & 8 to 12 & $400-500$ \\
LED & 6 to 9 & $400-500$ \\
\hline
\end{tabular}

\section{CONCLUSION}

Different light tubes are simulated and analysed by varying diameter, length and diffuser reactance. Simulation is done using a single light tube and double light tubes in a room. Simulation reslts show that single light tube is better as compared to double or two separate light tubes. Prototype of single light tube and double light tube have been designed and implemented for experimental purpose. Results obtained from experiments are compared with simulation.

\section{REFERENCES}

[1] R. Hopkinson, G. Petherbridge, Daylighting (1966).

[2] S. C. P. Plympton, K. Epstein. "Daylighting in schools: improving student performance and health at a price schools can afford," Proceedings of the American Solar Energy Society Conference, Madison, Wisconsin, 2000.

[3] G. Kim, J. T. Kim, "Healthy-daylighting design for the living environment in apartments in Korea," Building and Environment, vol. 45, no. 2, pp. 287-294, 2010.

[4] M. V. Lapsa, L. C. Maxey, D. D. Earl, D. L. Beshears, C. D. Ward, J. E. Parks, "Hybrid solar lighting provides energy savings and reduces waste heat," Energy Engineering, vol. 104, no. 4, pp. 7-20, 2007.

[5] L. Whitehead, "Overview of hollow light guide technologies and application," Proceedings in international conference on daylighting technologies for energy efficiency in buildings, 1998.

[6] P. Swift, G. Smith, "Cylindrical mirror light pipes," Solar Energy Materials and Solar Cells, vol. 36, no. 2, pp. 159-168, 1995.

[7] M. Kocifaj, S. Darula, R. Kittler, "Holigilm: Hollow light guide interior illumination method - an analytic calculation approach for cylindrical light-tubes," Solar energy, vol. 82, no. 3, pp. 247-259, 2008.

[8] D. Carter, "The measured and predicted performance of passive solar light pipe systems," Lighting Research and Technology, vol. 34, no. 1, pp. 39-51, 2002.

[9] S. Dutton, L. Shao, "Raytracing simulation for predicting light pipe transmittance," International Journal of LowCarbon Technologies, vol. 2, no. 4, pp. 339-358, 2007.

[10] L. Shao, A. A. Elmualim, I. Yohannes, "Mirror lightpipes: daylighting performance in real buildings," Lighting Research and Technology, vol. 30, no. 1, pp. 37-44, 1998.

[11] I. Yohannes. Evaluation of the performance of light-pipes used in offces. Nottingham University.

[12] G. Oakley, S. Riffat, L. Shao, "Daylight performance of lightpipes," Solar Energy, vol. 69, no. 2, pp. 89-98, 2000.

[13] D. M. Kennedy, F. ORourke, "Experimental analysis of a scaled, multiaperture, light-pipe, daylighting system," Solar Energy, vol. 122, pp. 181-190, 2015.

[14] X. Zhang, T. Muneer, J. Kubie, "A design guide for performance assessment of solar light-pipes," Lighting Research and Technology, vol. 34, no. 2, pp. 149-168, 2002.

[15] O. B. H. Hanneborg, Apparatus for transmitting sunlight to basements or other stories, US Patent 668,404, Feb. 19, 1901.

[16] M. Smart, J. Ballinger, "Tracking mirror beam sunlighting for deep interior spaces," Solar Energy, vol. 30, no. 6, pp. 527-536, 1983.

[17] C. Baroncini, O. Boccia, F. Chella, P. Zazzini, "Experimental analysis on a 1: 2 scale model of the double light pipe, an innovative technological device for daylight transmission," Solar energy, vol. 84, no. 2, pp. 296-307, 2010.

[18] I. Edmonds, G. Moore, G. Smith, P. Swift, "Daylighting enhancement with light pipes coupled to laser-cut lightdeecting panels," Lighting Research and Technology, vol. 27, no. 1, pp. 27-35, 1995.

[19] S. Darula, M. Kocifaj, J. Mohelnikova, "'Hollow light guide efficiency and illuminance distribution on the lighttube base under overcast and clear sky conditions," Optik-International Journal for Light and Electron Optics, vol. 124, no. 17, pp. 3165-3169, 2013.

[20] R. Canziani, F. Peron, G. Rossi, "Daylight and energy performances of a new type of light pipe," Energy and Buildings, vol. 36, no. 11, no. 1163-1176, 2004.

[21] D. Jenkins, T. Muneer, J. Kubie, "A design tool for predicting the performances of light pipes," Energy and buildings. vol. 37, no. 5, pp. 485-492, 2005.

[22] D. Jenkins, T. Muneer, "Modelling light-pipe performancesa natural daylighting solution," Building and Environment vol. 38, no. 7, pp. 965-972, 2003.

[23] C. Baroncini, F. Chella, P. Zazzini. "Numerical and experimental analysis of the double light pipe, a new system for daylight distribution in interior spaces," International Journal of Low-Carbon Technologies, vol. 3, no. 2, pp. 110-125, 2008.

[24] O. Boccia, F. Chella, P. Zazzini. "Numerical analysis on daylight transmission and thermal comfort in the environments containing devices called double light pipes," World Renewable Energy Congress- Sweden, 813 May, 2011. 
[25] M. Sabiha, R. Saidur, S. Mekhilef, O. Mahian, "Progress and latest developments of evacuated tube solar collectors," Renewable and Sustainable Energy Reviews, vol. 51, pp. 1038-1054, 2015.

[26] M. Al-Marwaee, D. Carter, "Tubular guidance systems for daylight: Achieved and predicted installation performances," Applied energy, vol. 83, no. 7, pp. 774-788, 2006.

[27] B. Malet-Damour, H. Boyer, A. H. Fakra, M. Bojic. "Light pipes performance prediction: inter model and experimental confrontation on vertical circular light-guides," Energy Procedia, vol. 57, pp. 1977-1986, 2014.

[28] M. R. Kumar, "A review of optical fibers for daylighting," International Journal of Instrumentation Electrical Electronics Engineering, vol. 1. no 2, Mar 2013.

[29] Light tube @ ONLINE (2016). [Online]. Available: https://en.wikipedia.org/wiki/Lighttube.

[30] L. Komar, S. Darula, "Determination of the light tube efficiency for selected overcast sky types," Solar Energy, vol. 86, vol. 1, pp. 157-163, 2012.

[31] T. J. Cox, P. D'antonio, Acoustic absorbers and diffusers: theory, design and application, Crc Press, 2009.

[32] C. Fischer, "Feedback on household electricity consumption: a tool for saving energy?," Energy efficiency, vol. 1, no. 1, pp. 79-104, 2008.

[33] B. Malet-Damour, H. Boyer, A. Fakra, M. Bojic, "Light pipes performance prediction: inter model and experimental confrontation on vertical circular light-guides," 2013 ISES solar world congress, 2013

[34] M. Kocifaj, F. Kundracik, "Luminous intensity solid of tubular light guide and its characterization using asymmetry parameter, "Solar Energy, vol. 85, no. 9, pp. 2003-2010, 2011.

[35] F. R. Dickson, D. P. Chevalier, M. Daley-Fell. Light-tube running board lighting, uS Patent 5,915,830 Jun. 29 1999.

[36] R. Hartungi, "Energy-efficient lighting design: A case study in an exclusive spa project," Journal of Building Appraisal, vol. 4, no. 4, pp. 287-299, 2009.

[37] M. V. Nielsen, S. Svendsen, L. B. Jensen, "Quantifying the potential of automated dynamic solar shading in office buildings through integrated simulations of energy and daylight," Solar Energy, vol. 85, no. 5, pp. 757-768, 2011.

[38] S. Chakraborty, "A comparative study on the consumption behaviour of modern technology lighting," in Globsyn Management Conference 2015, vol. 1, Allied Publishers, 2016, pp. 154.

[39] M. Reyasudin Basir Khan, J. Pasupuleti, J. Al-Fattah, and M. Tahmasebi, "Optimal gridconnected PV system for a campus microgrid," Indonesian Journal of Electrical Engineering and Computer Science (IJEECS), vol. 12, no. 3, pp. 899-906, 2018.

[40] S. Kumari, S. Y. Kumar, "A novel approach of controlling the solar pv integrated hybridmultilevel inverter," Indonesian Journal of Electrical Engineering and Informatics (IJEEI), vol. 6, no. 2, pp. 143-151, 2018.

[41] B. N. Mohapatra, M. R. Kumar, S. K. Mandal, R. K. Mohapatra, "Daylight factor analysiswith slat angle control for glare reduction in a three storied office building," InternationalJournal of Applied Engineering Research, vol. 13, no. 15, pp. 12040-12046, 2018.

[42] H. A. A. Wardeko, "Low cost solar energy efficiency for desalination system using simulationmatlab," Journal of Telematics and Informatics, vol. 6, no. 1, pp. 1-6, 2018.

\section{BIOGRAPHIES OF AUTHORS}

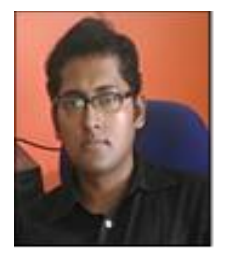

Badri Narayan Mohapatra started his research on communication in Centurian University, Odisha. He did his B.E. from Berhempur University and M.Tech from Biju Pattnaik University of Technology, Odisha. His research area covers Light propagation, Digital Signal and Image Processing.

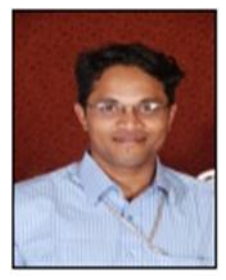

Dr. M. Ravi Kumar achieved his BE, Electronics \& Telecommunication in 2000 from Utkal Univ, MTech, Opto Electronics \& Laser Tech in 2005 from ISP, CUSAT, and obtained his Ph.D. on Optical CDMA codes in 2011 from IIT Kharagpur. His research interests include optical communication, integrated optics, visible light communication and daylighting. He has guided twelve M.Tech. theses and is currently supervising six research scholars and four M. Tech. students. His research interests Optical Communication, Optoelectronics, Solar energy, Optical Switching and Materials, Optical Switches \& Interconnects, Daylighting, Visible Light Communication.

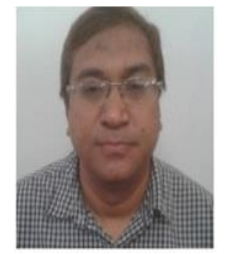

Dr. Sushanta Kumar Mandal received his B.E. degree in Electrical Engineering from Jalpaiguri Govt. Engineering College, West Bengal, India in 1993, MS and Ph. D degree from IIT, Kharagpur, India in 2002 and 2008 respectively. He has more than 17 years of teaching and industry experience. From August 2007 to June 2010, he worked as an Assistant Professor at DA-IICT, Gandhinagar. From July 2010-December 2014, he was professor in school of Electronics, KIIT University, BBSR. Former Professor at CUTM Bhubaneswar from 2015 to 2018, Currently he is working in Sharda University, India since December 2018. He has published more than 60 research papers in reputed journals and conferences. His research interests include modelling and synthesis of on-chip passive devices, digital, analog and mixedsignal CMOS VLSI design, high-level synthesis and soft computing applications in VLSI. 